
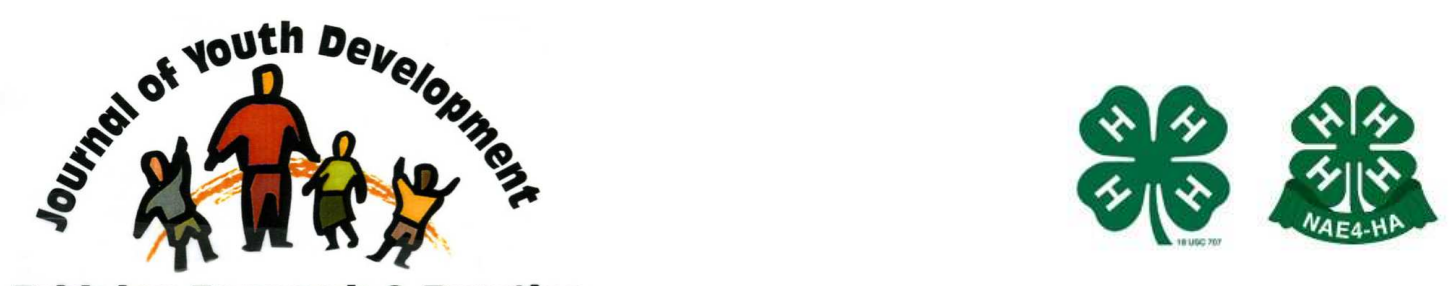

Bridging Research \& Practice

\title{
Parenting Practices that can Prevent or Reduce Childhood Obesity
}

\author{
Galen Eldridge \\ Department of Health and Human Development \\ Montana State University \\ Bozeman, MT \\ galen.eldridge@montana.edu \\ Wesley Lynch \\ Department of Psychology \\ Montana State University \\ Bozeman, MT \\ wlynch@montana.edu \\ Sandra Bailey \\ Department of Health and Human Development \\ Montana State University \\ Bozeman, MT \\ baileys@montana.edu \\ Carrie Benke \\ MSU Extension Health \& Human Development \\ Montana State University \\ Bozeman, MT \\ carrie.benke@montana.edu \\ Jill Martz \\ 4-H Center for Youth Development \\ Montana State University Extension \\ Bozeman, MT \\ jmartz@montana.edu \\ Lynn Paul \\ Department of Health and Human Development \\ Montana State University \\ Bozeman, MT \\ Ipaul@montana.edu
}




\title{
JOURNAL OF YOUTH DEVELOPMENT \\ bridging research and practice

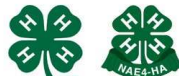

Bridging Research \& Practice

Volume 6, Number 2, Summer 2011

Article 110602FA001

\section{Parenting Practices that can Prevent or Reduce Childhood Obesity}

\author{
Galen Eldridge, Wesley Lynch, Sandra Bailey, Carrie Benke, \\ Jill Martz and Lynn Paul \\ Montana State University
}

\begin{abstract}
Overweight in children is more prevalent than ever before. What can parents do to try to promote health and prevent obesity in their own children? The present paper reviews research related to parenting and childhood obesity. The review describes what foodrelated parenting practices may be helpful: modeling healthy eating behaviors, making time for family meals, making sure healthy food is available and accessible, becoming aware of appropriate portion sizes, encouraging children to eat breakfast, and limiting soda and fast food intake. The paper also discusses food-related parenting practices that may not work to help prevent obesity: pressure to eat, food rewards, restriction, permissiveness, and modeling of unhealthy eating behaviors. Additional parenting practices such as supporting and engaging in physical activity, encouraging an adequate amount of sleep, and limiting television and other screen-media may also help children to maintain healthy weights. Suggestions are also given for professionals working with youth.
\end{abstract}

\section{Introduction}

Childhood obesity rates are at an all-time high and the general food environment is becoming increasingly conducive to eating more often, eating larger amounts, and eating more unhealthy foods. The goal of all parents is to raise healthy children, so what does recent research suggest works for them to provide a healthy food and activity environment for their family? This paper will review research related to parenting and childhood obesity. A discussion about what does work will be followed by what research has documented does not work to prevent or reduce childhood obesity. Implications for professionals working with youth will also be discussed. 


\section{Rationale}

Children today are less physically active and have less healthy diets than 25 years ago. Overweight children have numerous risk factors for cardiovascular disease, including high cholesterol, high blood pressure, and abnormal glucose tolerance. The causes of childhood obesity range from genetics, to environmental factors in homes, communities and schools, to economic influences of the food industry, to social and public policies. Because parents provide the most important psychosocial influences in the lives of children, making parents aware of factors they can control through resource-management, specific parenting practices, and role modeling will strengthen their positive influence, ultimately leading to a healthier lifestyle and beneficial long-term health consequences for children and families.

\section{Types of research}

Which kinds of studies provide the best evidence that a parenting practice is related to childhood obesity? There are various types of research design: laboratory experiments, in which one or two meals or snacks may be offered in various conditions; cross-sectional studies, which involve measurements or questionnaires at one time point; longitudinal or prospective studies, which involve measurements or questionnaires at two or more time points; and field experiments, in which a specific intervention is tested against another condition or against a nointervention control. Of these, field experiments provide the strongest evidence that a specific factor has a significant influence on childhood obesity, with long-term longitudinal studies providing the next strongest evidence (Ventura \& Birch, 2008).

\section{Eating practices and behaviors that may work to prevent or reduce childhood obesity}

There are many food-related practices that parents can model and encourage in order to promote healthy behaviors in their children. Some of these practices arise from authoritative, authoritarian, and permissive parenting styles (Baumrind, 1989) and corresponding parental feeding styles (Hughes, Power, Fisher, Mueller, \& Nicklas, 2005). The three types of parenting and feeding styles are: authoritative (firm, but warm and accepting), authoritarian (strict disciplinarians), and permissive (responsive, but not demanding). Of the three styles, authoritative parenting and feeding generally result in the most effective parental feeding practices.

Recommended authoritative parenting practices include making time for family meals, making sure healthy foods are more available and accessible than unhealthy foods, using preparation methods children prefer for healthy foods, assuring appropriate portion sizes, encouraging children to eat breakfast, minimizing soda and fast food consumption, and preparing and offering nutrient-dense, rather than energy-dense foods.

\section{Family meals}

Eating more meals in a family group has been correlated with higher diet quality (Woodruff, Hanning, McGoldrick \& Brown, 2010). In this case, dietary quality was calculated from 24-hour dietary recalls using the Healthy Eating Index, a measure of diet quality that assesses conformance to federal dietary guidance (Woodruff, et al., 2010). More specifically, eating family meals more frequently is correlated with greater intakes of fruits and vegetables, dairy products, vitamins, and minerals and consuming fewer soft drinks (e.g., Neumark-Sztainer, Larson, Fulkerson, Eisenburg, \& Story, 2010; Verzeletti, Maes, Santinello, Baldassari, \& Vereecken, 2010; Woodruff \& Hanning, 2008). Vegetables and dairy products served at family dinners have been shown to predict intake of vegetables and dairy products for youth five years 
later (Arcan, et al., 2007). Although children who eat family meals tend to have higher diet quality, watching television during family meals reduces or negates this benefit (Feldman, Eisenberg, Neumark-Sztainer, \& Story, 2007; Fitzpatrick, Edmunds, \& Dennison, 2007).

Most studies find that a greater proportion of family meals is associated with a lower prevalence of overweight among children (See reviews: Rhee, 2008; Woodruff \& Hanning, 2008). In one prospective study, children who ate fewer family meals were more likely to be overweight three years later (Gable, Chang, \& Krull, 2007).

It seems to make sense to recommend that families who eat meals together and who refrain from watching television during the family meal continue these practices. The parenting practice that seems to best support this recommendation is authoritative; parents are firm about eating together and not watching TV, but create a warm and supportive environment around the family table. It is also recommended that families who rarely eat together try to make time for more family meals.

\section{Availability of healthy or unhealthy foods}

Longitudinal and cross-sectional studies both show that exposure to and availability and accessibility of healthy foods can increase the preference for and intake of these foods (Pearson, Biddle, \& Gorely, 2009; Ventura \& Birch, 2008; Wind, te Velde, Brug, Sandvik, \& Klepp, 2010). Conversely, research has also shown that a permissive style of parenting that allows for availability of unhealthy food products at home is linked to children eating more total fat, sugar, and 'junk food,' and consuming more soft drinks (Gable \& Lutz, 2000; Haerens, et al., 2008; McClain, Chappuis, Nguyen-Rodriguez, Yaroch, \& Spruijt-Metz, 2009).

There are a variety of ways that parents can make healthy foods more accessible for children. These include strategies such as making sure that fruits and vegetables are available at various locations around the house, placing fruits and vegetables where children can easily reach them, preparing fruits and vegetables in sizes that are easy for children to eat, using fruits and vegetables for snacks instead of things like cookies and chips, including some form of fruit or vegetable in most meals, and buying fruits or vegetables instead of 'junk food' (O'Connor, et al., 2010). Giving children a choice between various fruits and vegetables will also help increase children's intake of these foods (Zeinstra, Koelen, Kok, van der Laan, \& de Graaf, 2010). Another study found that children who shop for fruits and vegetables with their parents eat more of these foods (Gross, Pollock, \& Braun, 2010).

\section{Preparation method}

The specific preparation method and resulting taste and texture of fruits and vegetables also affect how willing children are to eat them. For example, children tend to like crisp, crunchy, mild-tasting, and sweet vegetables and dislike strong and bitter tasting cooked ones (Sondergaard \& Edelenbos, 2007). They may also like vegetables served alone as a side dish, rather than in a mixed dish (Sondergaard \& Edelenbos, 2007). Although parents are encouraged to expose children to a variety of fruits and vegetables and preparation methods, they are also encouraged to take into consideration children's unique taste preferences. Negotiating and being willing to compromise are authoritative parenting practices.

\section{Portion size}

One study found that most children under the age of three will not eat a larger amount of food when they are served larger portions but that by the age of five this is no longer true (Rolls, Engell, \& Birch, 2000). However, another study found that children as young as two years old 
will eat more if they are served larger portions (Fisher, 2007). Parents need to be aware of the importance of portion sizes and what portion sizes are appropriate for their children.

One strategy for increasing the amount of fruits and vegetables eaten is to serve a larger portion of these foods, either as a first course or as a side dish (Kral, Kabay, Roe, \& Rolls, 2010; Spill, Birch, Roe, \& Rolls, 2010). Of course, serving smaller portions of desserts or other high calorie foods is also recommended. It is also recommended that parents model using internal cues for eating by cuing in to hunger as the signal to eat and fullness as the cue to stop eating. These internal cues of eating offer lifelong strategies to limiting portion sizes versus external cues of eating, such as cleaning the plate, as a cue to stop eating.

\section{Breakfast}

Breakfast eaters have higher daily intakes of vitamins and minerals and are more likely to meet nutrient intake recommendations than those who skip breakfast. (Rampersaud, Pereira, Girard, Adams, \& Metzl, 2005) Breakfast-skipping children and adolescents may have a lower diet quality overall than those who do not skip breakfast (Dubois, Girard, Kent, Farmer, \& TatoneTokuda, 2009; Storey, et al., 2009). This may be because those who skip breakfast do not 'make up' the missed nutrients later in the day.

A large number of cross-sectional studies have found that children and adolescents who often skip breakfast are more likely to be overweight than those who regularly eat breakfast (See reviews: Rampersaud, et al., 2005; Szajewska \& Ruszczynski, 2010). Prospectively, studies have found that adolescents who ate breakfast more often were less likely to be overweight or to have an increase in body mass index-for-age scores (BMI z-scores) or to become overweight 45 years later (Haerens, Vereecken, Maes, \& de Bourdeaudhuij, 2010; Merten, Williams, \& Shriver, 2009; Niemeier, Raynor, Lloyd-Richardson, Rogers, \& Wing, 2006; Timlin, Pereira, Story, \& Neumark-Sztainer, 2008). For example, one study found a significant inverse relationship between BMI z-score and frequency of breakfast consumption when students were measured over four years, from age 10 to age 14 (Haerens, et al., 2010).

Lack of time, lack of hunger, and lack of appeal are some of the reasons kids give for not eating breakfast. An excellent idea for school nights is for parents to ask their kids to talk about what would be appealing for breakfast and possibly prepare healthy 'on-the-go' breakfasts together for the next morning. Again, this is an example of an authoritative parenting practice. Some studies have found that lower meal frequency in general, or skipping meals, rather than simply skipping breakfast, is correlated with greater overweight or obesity (See reviews: Koletzko \& Toschke, 2010; Patro \& Szajewska, 2010). In general parents should discourage children from skipping meals for any reason, but especially as a weight control strategy. Contrary to expectation, skipping meals does not prevent weight gain and may produce the opposite result.

\section{Soft drinks and other sugar-sweetened beverages}

Recent reviews have summarized evidence showing a detrimental effect of soft drink consumption on body weight in childhood (Harrington, 2008; Libuda \& Kersting, 2009; Must, Barish, \& Bandini, 2009). Although some studies have focused only on soft drinks, others have also included other sweetened beverages such as 'fruit drinks,' sports drinks, sweetened tea, and other beverages that contain added sweeteners. In one study, which included beverages other than soft drinks, sweetened beverage intake at age 5 was positively associated with overweight at ages 5, 7, 9, 11, 13, and 15 (Fiorito, Marini, Francis, Smiciklas-Wright, \& Birch, 2009). 
Some intervention studies have shown that a reduction in soft drink consumption by as little as one-third cup per day can lead to a reduction of overweight and obesity (Ebbeling, et al., 2006; James, Thomas, Cavan, \& Kerr, 2004). For example, a 1-year randomized trial in which one group of children decreased the consumption of sugar-sweetened carbonated beverages by one-third cup per day resulted in a significant reduction of overweight compared to a comparable group of children who did not receive the intervention (James, et al., 2004).

Soft drinks should be discouraged as an 'every day' beverage, especially for young children. But instead of completely eliminating soft drinks, which would be considered an authoritarian parenting practice, parents could offer them occasionally to older children, reflecting an authoritative style of parenting. Parents may want to discourage children's regular consumption of other sweetened beverages as well; examples of these include sports or 'energy' drinks, 'fruit drinks' that contain less than $100 \%$ fruit juice, and sweetened tea or coffee.

\section{Fast food}

Fast food consumption is unequivocally associated with higher energy intake, making children more susceptible to weight gain and obesity, according to a recent review (Rosenheck, 2008). Both cross-sectional and prospective studies have come to this conclusion (See review: Rosenheck, 2008; Viner \& Cole, 2006). Children who eat more fast food not only consume more total calories, they also consume more fat and sugar-sweetened beverages and less fiber, milk, fruit and non-starchy vegetables (See reviews: Newby, 2007; Rosenheck, 2008). Similarly, individual children consume more total energy and have poorer diet quality on days with, compared to days without, fast food (Bowman, Gortmaker, Ebbeling, Pereira, \& Ludwig, 2004; Paeratakul, Ferdinand, Champagne, Ryan, \& Bray, 2003).

Convenience, low cost, and taste appeal of high-fat, high-sugar foods contribute to the popularity of fast foods. A suggestion for parents is to plan ahead, making sure the ingredients are on hand for quick healthy snacks and meals. Parents and children should also be encouraged to learn about and seek out the healthiest options at fast food outlets.

\section{Energy density and nutrient density}

Energy density refers the number of calories in a given amount of food. Energy dense foods have more calories per unit volume and often provide few nutrients. Nutrient density refers to the ratio of nutrients to the number of calories in a food; in other words, nutrient-dense foods contain more nutrients per bite than nutrient-poor foods.

Reducing the energy density of food decreases children's energy intake. For example, when children were offered a lower fat version of macaroni and cheese, they consumed the same weight of the food as when they were offered the higher fat version, resulting in significantly less energy consumption (Leahy, Birch, \& Rolls, 2008). Another way to reduce the energy density of a dish is to add vegetables. This too, resulted in lower energy intake during a test meal, with the added benefit of an increase in vegetable intake (Leahy, Birch, Fisher, \& Rolls, 2008). Longitudinal studies have also found a positive association between the energy density of children's diets and future body fatness (Johnson, Mander, Jones, Emmett, \& Jebb, 2008; McCaffrey, et al., 2008).

If parents are concerned about their children overeating, they should realize that energy density is another factor they can control during meal preparation. Knowing and discouraging foods with high energy density and promoting those with high nutrient density are positive steps for 
parents to take. However, it is important to remember that just as with sweets, high fat foods are occasionally acceptable to consume.

\section{Eating practices and behaviors that do not work to prevent or reduce childhood obesity}

Recent research has shown that many practices parents employ in an attempt to assist their children in developing healthy eating practices are not successful. Some are even detrimental. These practices include pressuring children to eat, using food rewards, restricting foods, being overly permissive, and modeling unhealthy food practices.

\section{Pressure to eat}

Parental pressure to eat, an authoritarian feeding practice, may result in a disruption to children's self-regulation of food intake, lower dietary quality, and heavier weight. As mentioned earlier, when parents encourage kids to 'join the clean plate club' (i.e., eat everything on their plate), they are unintentionally teaching kids to pay more attention to external cues (e.g., food on plate or verbal instructions) than internal ones (e.g., hunger and fullness) (Birch, McPhee, Shoba, Steinberg, \& Krehbiel, 1987).

Similarly, youth whose parents pressure or prompt them to eat end up eating fewer fruits and vegetables overall and eat more sweets than those whose parents do not pressure them to eat (e.g., Vereecken, Legiest, de Bourdeaudhuij, \& Maes, 2009).

There is also some evidence to suggest that those whose parents pressure them to eat are more likely to be or become overweight (Birch \& Fisher, 1998; Klesges, et al., 1983). This suggests that parental pressure to eat is not a helpful strategy in terms of teaching selfregulation of energy intake, good dietary choices, or healthy weight maintenance.

\section{Use of food rewards}

Likewise, another authoritarian feeding practice, using food rewards to encourage children to eat healthy foods (for example, requiring that vegetables be eaten before dessert) leads to the development of dislike for the healthy foods and increases the importance of and preference for the reward foods (in this case, dessert) (See review: Ventura \& Birch, 2008). Rewarding with food leads to an increase in the consumption of unhealthy foods by children (Kroller \& Warschburger, 2009) and a decrease in consumption of fruits and vegetables (Kroller \& Warschburger, 2008). Like pressure to eat, use of food rewards is not recommended, as it seems detrimental to children's self-regulation in making healthy food choices.

\section{Permissiveness}

Although too much parent pressure to eat or restriction of certain foods can lead to overeating and overweight, so too can being excessively permissive about what kids can eat. Parents who use a permissive feeding style may provide few restrictions and let their children choose what and when to eat. Kids whose parents employ this feeding style eat fewer fruits and vegetables and more sweets and consume more soft drinks (Hoerr, et al., 2009; Mendoza, Drewnowski, Cheadle, Christakis, 2006; Vereecken, et. al., 2009). A permissive feeding style is also associated with a higher risk of child overweight (e.g., Hennessy, Hughes, Goldberg, Hyatt, \& Economos, 2010). Parents must therefore learn an appropriate balance between being too restrictive and too permissive. 


\section{Restriction}

Another tactic that seems to make intuitive sense to many parents is restricting access to unhealthy foods. Unfortunately, studies have shown that kids then may pay attention to and eat more of the unhealthy foods when they are available, even if they are not hungry (See review: Anzman, Rollins, \& Birch, 2010). For example, greater control by parents over their children's eating has been linked to greater fat intake by the children (Zive, et al., 1998).

Greater parental food restriction has also been linked to overeating, weight gain, a greater tendency to eat in the absence of hunger, and lower ability to self-regulate energy intake, (See reviews: Anzman et al., 2010; Kral \& Rauh, 2010; Ventura \& Birch, 2008). It has generally been found that parents whose children are overweight or who are concerned about their children being overweight are more likely to use food restriction (e. g., Gregory, et al., 2010; Santos, et al., 2009). Indeed, in a dinnertime meal observation study parents of overweight children used restriction twice as often as parents of children who were not overweight (Moens, Braet, \& Soetens, 2007).

Whether restriction causes overweight is unclear. For instance, there is some evidence that parents use controlling (authoritarian) feeding practices after, not before, their children become overweight (Rhee, et al., 2009). Conversely, other evidence shows that parents who are concerned about their children becoming overweight, but who are not currently overweight, are more likely to use restrictive feeding practices (May, et al., 2007).

Again, parents must find a balance between being too permissive and too restrictive. Some parents, for example, provide a single serving of dessert with the dinner meal. This may communicate to children that desserts are less important than the meal itself; they are just part of the meal, like the vegetables or beans or meat. Other parents find that serving their children's favorite indulgence foods once or twice per week teaches children that, while they do not have these foods all the time, they will get them on a regular basis; this is also an acceptable practice.

\section{Parental eating behavior}

It makes sense that parents' eating behaviors would affect what kids eat. Parent modeling, in fact, has been related to higher intake of healthy foods and lower intake of unhealthy foods (Kroller \& Warschburger, 2009). Studies have found parent-child correlations with respect to the consumption amount or consumption frequency of milk (Fisher, Mitchell, Smiciklas-Wright, Mannino, \& Birch, 2004), sweetened beverages, (Fisher, et al., 2004; McClain, et al., 2009), fat (Wang, Beydoun, Li, Liu, \& Moreno, 2011), fiber (Vagstrand, 2010), and fruits and vegetables (See reviews: Coulthard \& Blissett, 2009; Geller \& Dzewaltowski, 2009; Pearson, et al., 2009). One longitudinal study found that mothers' weekly consumption of fruits and vegetables was a positive predictor of their children's weekly consumption of fruit and vegetable intake four years later (Vereecken, Haerens, de Bourdeaudhuij, \& Maes, 2010).

Research has also shown positive correlations between parents' emotional eating and adolescents' emotional eating (Lauzon-Guillain, et al., 2009; Snoek, Engels, Janssens, \& van Strien, 2007), as well as between parents' emotional eating and preschoolers' eating in the absence of hunger (Blisset, Haycraft, \& Farrow, 2010). Children's external eating tendencies, or eating in response to external food cues like the sight and smell of foods, are also related to those of their parents (Elfhag, Tynelius, \& Rasmussen, 2010; Zocca, et al., 2010). 
Although children may resemble their parents in terms of external eating tendencies, they can be taught to recognize and eat in response to internal hunger cues. For example, a six-week intervention study was successful in teaching preschoolers to recognize internal hunger cues, after which they were better able to self-regulate their food intake during a laboratory test meal (Johnson, 2000). Parents can present concrete, developmentally appropriate definitions to their children for hunger and fullness that can be linked to their children's own internal feelings of hunger and satiety. Children can then be encouraged to attend to cues of hunger and fullness before, during, and after meals and snacks.

Parents may not realize how much their own eating habits influence the eating habits of their children and may not be fully aware of their own eating behavior. Therefore parents should be encouraged to monitor their own eating and to model healthful eating as much as possible. Such modeling might include moderation in eating sweets and high fat foods and reduction in emotional eating and eating solely in response to external food cues. Learning self-monitoring and self-regulation, of course, requires effort and practice.

In summary, in order to provide a healthy eating environment, parents might be encouraged to adopt characteristics of authoritative parents or an authoritative feeding style - being both firm with expectations and responsive. In other words, parents can be assertive, but can also negotiate, compromise, and explain expectations to their children rather than simply demanding compliance. For example, one study found that negotiation with children on food choices and rules increased the likelihood of daily consumption of vegetables (Vereecken, et al., 2009).

\section{Physical activity, sedentary activity, and sleep behaviors that influence childhood obesity}

Parents not only influence the food environment of their children, but also the activity and sleep-related aspects of their children's environment. They can model, support, and encourage physical activity, help to reduce time spent in sedentary activities, and encourage appropriate amounts of sleep for their children. Each of these can reduce or prevent childhood obesity.

\section{Physical activity}

Not surprisingly, kids' activity levels (from preschool age to adolescence) are positively correlated with their parents' activity levels (See review: Edwardson \& Gorely, 2010). One study found that girls who reported their parents exercised at least three times per week were about $50 \%$ more active than girls with sedentary parents (Madsen, McCulloch, \& Crawford, 2009).

Along with modeling, parental encouragement and logistical support are positively correlated with children's amount of physical activity (See reviews: Edwardson \& Gorely, 2010; Beets, Cardinal, \& Alderman, 2010). Although adolescent girls' physical activity levels tend to decrease during the middle school and high school years, longitudinal studies have found that family support may mediate this trend (Davison \& Jago, 2009; Dowda, Dishman, Pfeiffer, \& Pate, 2007). Family support was either defined simply as 'logistical support' (Davison \& Jago, 2009) or as the weekly frequency with which other family members encouraged, participated in, provided transportation for, or watched the child's physical activity, or told the child that physical activity was good for him or her (Dowda, et al., 2007).

One study found that parents who talked to their adolescents or attended activities with them (not necessarily sports or exercise-related) had children who participated in more physical activity, (Ornelas, Perreira, \& Ayala, 2007); so even generally communicating and engaging 
with adolescents appears to be related to their increasing activity level. The amount of time spent outdoors is also highly related to the amount of kids' physical activity (Cleland, et al., 2008; Nilsson, et al., 2009; See review: Sallis, Prochaska, \& Taylor, 2000). Parents have a role in influencing the amount of time their children spend outside; they can offer support for and encourage outdoor activities. The home environment can also be conducive to physical activity. One longitudinal study found that, for 10-12 year olds, a higher number of physical activity equipment items at home was related to decreases in BMI z-scores three years later (Timperio et al, 2008).

Parents have many ways to influence their children's physical activity. They can pay or request scholarships for sports fees, provide or arrange transportation to sports practices or other places where their children can be active, regularly make time to be active as a family, and make an effort to get an adequate amount of exercise themselves. They can also work to make their homes and schools conducive to physical activity and encourage their children to spend more time outdoors.

\section{Television and sedentary activity}

A large number of cross-sectional and prospective studies have noted a relationship between heavy television viewing and childhood overweight (See reviews: Jordan \& Robinson, 2008; Rey-Lopez, Vicente-Rodriguez, Biosca, \& Moreno, 2008). For example, one study found that for each additional hour of television viewed per day, a child was three times more likely to be obese (Gable \& Lutz, 2000). In randomized controlled trials, reducing the number of hours spent viewing television and other screen media has been related to a decrease in BMI and overweight, as well as weight loss among overweight children (Jordan \& Robinson, 2008).

Parents are not only models of physical activity, but also of inactivity. The more parents watch television, engage in other leisure time screen-related sedentary activities, or simply spend time being inactive, the higher the risk is that their children will too (e.g., He, Harris, Piche, \& Beynon, 2009; Jago, Fox, Page, Brockman, \& Thompson, 2010).

Studies have shown that hours of television watched are positively associated with increased intake of nutrient-poor, energy-dense foods, and greater overall energy intake (See review: Shea, Harvey-Berino, \& Johnson, 2010). Furthermore, two intervention studies found that when children and adolescents decrease the amount of time they spend in sedentary activities, their fat intake and total energy intake decrease as well (Epstein, Roemmich, Paluch, \& Raynor, 2005; Epstein, et al., 2008).

A larger number of sedentary items at home (for example, televisions, DVD players, computers, electronic games) has also been positively associated with children's BMI (Crawford, et al., 2010) and is predictive of greater increases in BMI z-scores over three years (Timperio et al, 2008).

An expert panel recommends eliminating televisions from children's bedrooms, turning off the television while eating, and budgeting television time (Jordan \& Robinson, 2008). While completely eliminating a television from the bedroom may not be practical, parents and children can work together on viable solutions that promote healthier viewing habits.

\section{Sleep}

The relationship between diet quality and sleep duration has also been studied. In general, it has been found that 'short' sleepers consumed a higher proportion of calories from fat (Weiss, 
et al., 2010) and more energy rich foods, such as fast food, sweets, and soft drinks (Hitze, et al., 2009; Westerlund, Ray, \& Roos, 2009).

The relationship between sleep and overweight has received attention in the last few years. Two 2008 reviews of cross-sectional studies found that shorter sleep duration is associated with greater overweight in children and adolescents (Marshall, Glozier, \& Grunstein, 2008; Patel \& $\mathrm{Hu}, 2008$ ). More recent studies have also found this to be true (e.g., Shi, et al., 2010). For example, one cross-sectional study of 5-15 year olds found that the risk of children being obese was doubled for those who slept less than nine hours per night compared with those who slept 10 or more hours each night. (Shi, et al., 2010)

Longitudinal studies have resulted in similar findings to these cross-sectional studies. Toddlers and children who slept fewer hours were more likely to be overweight three to six years later (Bell \& Zimmerman, 2010; Lumeng, et al., 2007; Marshall et al., 2008) and adolescents whose sleep duration decreased during puberty were more likely to experience an increase in BMI during that same period (Rutters, Gerver, Nieuwenhuizen, Verhoef, \& Westerterp-Plantenga, 2010). Another notable study found that short sleep duration in childhood predicted obesity at age 32 (Landhuis, Poulton, Welch, \& Hancox, 2008).

It seems prudent to recommend that parents encourage their children to get enough sleep, for example by ensuring a regular bedtime routine, removing televisions from children's bedrooms, and making sure bedrooms are quiet, dark, relaxing, and a comfortable temperature. Having children complete homework early and reducing sources of worry or stress may also lead to better and longer periods of sleep.

\section{Implications and Conclusions}

Research has clearly demonstrated that there are dietary and physical activity behaviors that families can adopt to encourage healthfulness and which can reduce or prevent childhood overweight. Regarding food-related behaviors, parents are encouraged to provide access to nutrient-dense foods and beverages for meals and snacks, reduce access to high-calorie, nutrient-poor beverages and foods at home and at restaurants, and avoid excessive food restriction or use of food rewards, as well as modeling healthful eating. In the activity realm, parents can provide opportunities and encouragement for children to be physically active, reduce children's television and video game time, and model healthy physical activity practices to reinforce these patterns in youth.

Professionals working with families can support parents in these efforts.

- At youth gatherings, such as 4-H meetings, provide healthy refreshments. Examine what types of foods are being sold by the youth groups for school fundraisers or at fairs and other events. Strategize with others about how to change sales so that foods are more nutritious.

- Offer parents handouts with tips to help their children develop healthy eating practices based on the research presented in this article. Develop a recipe sharing venue for parents where they can exchange ideas for nutritious and appealing meals and snacks.

- Build in physical activity to youth meetings and events. Assign a youth member to lead a short physical activity at meetings. Brainstorm with youth and their parents for ideas of how they can be active for one hour a day. Ideas may include walking the dog together each evening or walking out to feed livestock rather than riding in a vehicle. 
- Be a community advocate and resource for offering better school lunches and limiting access to school vending machines with unhealthy food choices. Advocate for healthy concession stand options at school and community events.

Parents and professionals working together with youth can strive to offer more nutritious meals and snacks, increase physical activity, and model healthy living. Working together to change the culture of nutrition and physical activity can reduce or prevent obesity in youth.

Note: A comprehensive list of related articles is available upon request. Contact Galen Eldridge, Department of Health and Human Development, Montana State University, galen.eldridge@montana.edu

\section{References}

Anzman, S.L., Rollins, B.Y., \& Birch, L.L. (2010). Parental influence on children's early eating environments and obesity risk: implications for prevention. International Journal of Obesity, 34, 1116-1124.

Arcan, C., Neumark-Sztainer, D., Hannan, P., van den Berg, P., Story, M., \& Larson, N. (2007). Parental eating behaviours, home food environment and adolescent intakes of fruits, vegetables and dairy foods: longitudinal findings from Project EAT. Public Health Nutrition, 10, 1257-1265.

Baumrind, D. (1989). Rearing competent children. In Damon W (Ed.), Child Development Today and Tomorrow (pp. 349-378). San Francisco, CA: Josey-Bass.

Beets, M.W., Cardinal, B.J., \& Alderman, B.L. (2010). Parental Social Support and the Physical Activity-Related Behaviors of Youth: A Review. Health Education and Behavior, 37, 621-644.

Bell, J.F., \& Zimmerman, F.J. (2010). Shortened Nighttime Sleep Duration in Early Life and Subsequent Childhood Obesity. Archives of Pediatrics \& Adolescent Medicine, 164, 840-845.

Birch, L.L., McPhee, L., Shoba, B.C., Steinberg, L., \& Krehbiel, R. (1987). Clean Up Your Plate Effects of Child Feeding Practices on the Conditioning of Meal Size. Learning and Motivation, 18, 301-317.

Birch, L.L., \& Fisher, J.O. (1998). Development of eating behaviors among children and adolescents. Pediatrics, 101, 539-549.

Blissett, J., Haycraft, E., \& Farrow, C. (2010). Inducing preschool children's emotional eating: relations with parental feeding practices. American Journal of Clinical Nutrition, 92, 359-365.

Bowman, S.A., Gortmaker, S.L., Ebbeling, C.B., Pereira, M.A., \& Ludwig, D. S. (2004). Effects of fast-food consumption on energy intake and diet quality among children in a national household survey. Pediatrics, 113, 112-118.

Cleland, V., Crawford, D., Baur, L. A., Hume, C., Timperio, A., \& Salmon, J. (2008). A prospective examination of children's time spent outdoors, objectively measured physical activity and overweight. International Journal of Obesity, 32, 1685-1693. 
Coulthard, H., \& Blissett, J. (2009). Fruit and vegetable consumption in children and their mothers. Moderating effects of child sensory sensitivity. Appetite, 52, 410-415.

Crawford, D., Cleland, V., Timperio, A., Salmon, J., Andrianopoulos, N., Roberts, R., et al. (2010). The longitudinal influence of home and neighbourhood environments on children's body mass index and physical activity over 5 years: the CLAN study. International Journal of Obesity, 34, 1177-1187.

Davison, K.K., \& Jago, R. (2009). Change in Parent and Peer Support across Ages 9 to $15 \mathrm{yr}$ and Adolescent Girls' Physical Activity. Medicine and Science in Sports and Exercise, 41, 18161825 .

Dowda, M., Dishman, R.K., Pfeiffer, K.A., \& Pate, R.R. (2007). Family support for physical activity in girls from 8th to 12th grade in South Carolina. Preventive Medicine, 44, 153-159.

Dubois, L., Girard, M., Kent, M.P., Farmer, A., \& Tatone-Tokuda, F. (2009). Breakfast skipping is associated with differences in meal patterns, macronutrient intakes and overweight among preschool children. Public Health Nutrition, 12, 19-28.

Ebbeling, C.B., Feldman, H.A., Osganian, S.K., Chomitz, V.R., Ellenbogen, S.J., \& Ludwig, D.S. (2006). Effects of decreasing sugar-sweetened beverage consumption on body weight in adolescents: A randomized, controlled pilot study. Pediatrics, 117, 673-680.

Edwardson, C.L. \& Gorely, T. (2010). Activity-Related Parenting Practices and Children's Objectively Measured Physical Activity. Pediatric Exercise Science, 22, 105-113.

Elfhag, K., Tynelius, P., \& Rasmussen, F. (2010). Family links of eating behaviour in normal weight and overweight children. International Journal of Pediatric Obesity, 5, 491-500.

Epstein, L.H., Roemmich, J.N., Paluch, R.A., \& Raynor, H.A. (2005). Influence of changes in sedentary behavior on energy and macronutrient intake in youth. American Journal of Clinical Nutrition, 81, 361-366.

Epstein, L.H., Roemmich, J.N., Robinson, J.L., Paluch, R.A., Winiewicz, D.D., Fuerch, J.H., et al. (2008). A randomized trial of the effects of reducing television viewing and computer use on body mass index in young children. Archives of Pediatrics \& Adolescent Medicine, 162, 239-245.

Feldman, S., Eisenberg, M.E., Neumark-Sztainer, D., \& Story, M. (2007). Associations between watching TV during family meals and dietary intake among adolescents. Journal of Nutrition Education and Behavior, 39, 257-263.

Fiorito, L.M., Marini, M., Francis, L.A., Smiciklas-Wright, H., \& Birch, L.L. (2009). Beverage intake of girls at age 5 y predicts adiposity and weight status in childhood and adolescence. American Journal of Clinical Nutrition, 90, 935-942.

Fisher, J.O., Mitchell, D.C., Smiciklas-Wright, H., Mannino, M.L., \& Birch, L.L. (2004). Meeting calcium recommendations during middle childhood reflects mother-daughter beverage choices and predicts bone mineral status. American Journal of Clinical Nutrition, 79, 698-706. 
Fisher, J.O. (2007). Effects of age on children's intake of large and self-selected food portions. Obesity, 15, 403-412.

Fitzpatrick, E., Edmunds, L.S., \& Dennison, B.A. (2007). Positive effects of family dinner are undone by television viewing. Journal of the American Dietetic Association, 107, 666-671.

Gable, S., \& Lutz, S. (2000). Household, parent, and child contributions to childhood obesity. Family Relations, 49, 293-300.

Gable, S., Chang, Y., \& Krull, J.L. (2007). Television watching and frequency of family meals are predictive of overweight onset and persistence in a national sample of school-aged children. Journal of the American Dietetic Association, 107, 53-61.

Geller, K.S., \& Dzewaltowski, D.A. (2009). Longitudinal and cross-sectional influences on youth fruit and vegetable consumption. Nutrition Reviews, 67, 65-76.

Gregory, J.E., Paxton, S.J., \& Brozovic, A.M. (2010). Pressure to eat and restriction are associated with child eating behaviours and maternal concern about child weight, but not child body mass index, in 2-to 4-year-old children. Appetite, 54, 550-556.

Gross, S.M., Pollock, E.D., \& Braun, B. (2010). Family Influence: Key to Fruit and Vegetable Consumption among Fourth- and Fifth-grade Students. Journal of Nutrition Education and Behavior, 42, 235-241.

Haerens, L., Craeynest, M., Deforche, B., Maes, L., Cardon, G., \& de Bourdeaudhuij, I. (2008). The contribution of psychosocial and home environmental factors in explaining eating behaviours in adolescents. European Journal of Clinical Nutrition, 62, 51-59.

Haerens, L., Vereecken, C., Maes, L., \& de Bourdeaudhuij, I. (2010). Relationship of physical activity and dietary habits with body mass index in the transition from childhood to adolescence: a 4-year longitudinal study. Public Health Nutrition, 13, 1722-1728.

Harrington, S. (2008). The Role of Sugar-Sweetened Beverage Consumption in Adolescent Obesity: A Review of the Literature. Journal of School Nursing, 24, 3-12.

He, M.Z., Harris, S., Piche, L., \& Beynon, C. (2009). Understanding Screen-Related Sedentary Behavior and Its Contributing Factors Among School-Aged Children: A Social-Ecologic Exploration. American Journal of Health Promotion, 23, 299-308.

Hennessy, E., Hughes, S.O., Goldberg, J.P., Hyatt, R.R., \& Economos, C.D. (2010). Parent behavior and child weight status among a diverse group of underserved rural families. Appetite, 54, 369-377.

Hitze, B., Bosy-Westphal, A., Bielfeldt, F., Settler, U., Plachta-Danielzik, S., Pfeuffer, M., et al. (2009). Determinants and impact of sleep duration in children and adolescents: data of the Kiel Obesity Prevention Study. European Journal of Clinical Nutrition, 63, 739-746.

Hoerr, S.L., Hughes, S.O., Fisher, J.O., Nicklas, T.A., Liu, Y., \& Shewchuk, R.M. (2009). Associations among parental feeding styles and children's food intake in families with limited incomes. International Journal of Behavioral Nutrition and Physical Activity, 6. 
Hughes, S.O., Power, T.G., Fisher, J.O., Mueller, S., \& Nicklas, T.A. (2005). Revisiting a neglected construct: parenting styles in a child-feeding context. Appetite, 44, 83-92.

Jago, R., Fox, K.R., Page, A.S., Brockman, R., \& Thompson, J.L. (2010). Parent and child physical activity and sedentary time: Do active parents foster active children? Bmc Public Health, 10.

James, J., Thomas, P., Cavan, D., \& Kerr, D. (2004). Preventing childhood obesity by reducing consumption of carbonated drinks: cluster randomised controlled trial. British Medical Journal, 328, 1237-1239.

Johnson, L., Mander, A.P., Jones, L.R., Emmett, P.M., \& Jebb, S.A. (2008). A prospective analysis of dietary energy density at age 5 and 7 years and fatness at 9 years among UK children. International Journal of Obesity, 32, 586-593.

Johnson, S.L. (2000). Improving preschoolers' self-regulation of energy intake. Pediatrics, 106, 1429-1435.

Jordan, A.B., \& Robinson, T.N. (2008). Children, television viewing, and weight status: Summary and recommendations from an expert panel meeting. Annals of the American Academy of Political and Social Science, 615, 119-132.

Klesges, R.C., Coates, T.J., Brown, G., Sturgeontillisch, J., Moldenhauerklesges, L.M., Holzer, B., et al. (1983). Parental Influences on Children's Eating Behavior and Relative Weight. Journal of Applied Behavior Analysis, 16, 371-378.

Koletzko, B., \& Toschke, A.M. (2010). Meal Patterns and Frequencies: Do They Affect Body Weight in Children and Adolescents? Critical Reviews in Food Science and Nutrition, 50, 100105.

Kral, T.V.E., \& Rauh, E. M. (2010). Eating behaviors of children in the context of their family environment. Physiology \& Behavior, 100, 567-573.

Kral, T.V.E., Kabay, A.C., Roe, L.S., \& Rolls, B.J. (2010). Effects of Doubling the Portion Size of Fruit and Vegetable Side Dishes on Children's Intake at a Meal. Obesity, 18, 521-527.

Kroller, K., \& Warschburger, P. (2008). Associations between maternal feeding style and food intake of children with a higher risk for overweight. Appetite, 51, 166-172.

Kroller, K., \& Warschburger, P. (2009). Maternal feeding strategies and child's food intake: considering weight and demographic influences using structural equation modeling. International Journal of Behavioral Nutrition and Physical Activity, 6.

Landhuis, C.E., Poulton, R., Welch, D., \& Hancox, R.J. (2008). Childhood Sleep Time and LongTerm Risk for Obesity: A 32-Year Prospective Birth Cohort Study. Pediatrics, 122, 955-960.

Lauzon-Guillain, B., Romon, M., Musher-Eizenman, D., Heude, B., Basdevant, A., Charles, M.A., et al. (2009). Cognitive restraint, uncontrolled eating and emotional eating: correlations between parent and adolescent. Maternal and Child Nutrition, 5, 171-178.

Leahy, K.E., Birch, L.L., Fisher, J.O., \& Rolls, B.J. (2008). Reductions in entree energy density increase children's vegetable intake and reduce energy intake. Obesity, 16, 1559-1565. 
Leahy, K.E., Birch, L.L., \& Rolls, B.J. (2008). Reducing the energy density of an entree decreases children's energy intake at lunch. Journal of the American Dietetic Association, 108, 41-48.

Libuda, L., \& Kersting, M. (2009). Soft drinks and body weight development in childhood: is there a relationship? Current Opinion in Clinical Nutrition and Metabolic Care, 12, 596-600.

Lumeng, J.C., Somashekar, D., Appugliese, D., Kaciroti, N., Corwyn, R.F., \& Bradley, R.H. (2007). Shorter sleep duration is associated with increased risk for being overweight at ages 9 to 12 years. Pediatrics, 120, 1020-1029.

Madsen, K.A., McCulloch, C.E., \& Crawford, P.B. (2009). Parent Modeling: Perceptions of Parents' Physical Activity Predict Girls' Activity throughout Adolescence. Journal of Pediatrics, $154,278-283$.

Marshall, N.S., Glozier, N., \& Grunstein, R.R. (2008). Is sleep duration related to obesity? A critical review of the epidemiological evidence. Sleep Medicine Reviews, 12, 289-298.

May, A.L., Donohue, M., Scanlon, K.S., Sherry, B., Dalenius, K., Faulkner, P., et al. (2007). Child-feeding strategies are associated with maternal concern about children becoming overweight, but not children's weight status. Journal of the American Dietetic Association, 107, 1167-1174.

McCaffrey, T.A., Rennie, K.L., Kerr, M.A., Wallace, J.M., Hannon-Fletcher, M.P., Coward, W.A., et al. (2008). Energy density of the diet and change in body fatness from childhood to adolescence; is there a relation? American Journal of Clinical Nutrition, 87, 1230-1237.

McClain, A.D., Chappuis, C., Nguyen-Rodriguez, S.T., Yaroch, A.L., \& Spruijt-Metz, D. (2009). Psychosocial correlates of eating behavior in children and adolescents: a review. International Journal of Behavioral Nutrition and Physical Activity, 6.

Mendoza, J.A., Drewnowski, A., Cheadle, A., \& Christakis, D.A. (2006). Dietary energy density is associated with selected predictors of obesity in US children. Journal of Nutrition, 136, 13181322.

Merten, M.J., Williams, A.L., \& Shriver, L.H. (2009). Breakfast Consumption in Adolescence and Young Adulthood: Parental Presence, Community Context, and Obesity. Journal of the American Dietetic Association, 109, 1384-1391.

Moens, E., Braet, C., \& Soetens, B. (2007). Observation of family functioning at mealtime: A comparison between families of children with and without overweight. Journal of Pediatric Psychology, 32, 52-63.

Must, A., Barish, E.E., \& Bandini, L.G. (2009). Modifiable risk factors in relation to changes in BMI and fatness: what have we learned from prospective studies of school-aged children? International Journal of Obesity, 33, 705-715.

Neumark-Sztainer, D., Larson, N.I., Fulkerson, J.A., Eisenberg, M.E., \& Story, M. (2010). Family meals and adolescents: what have we learned from Project EAT (Eating Among Teens)? Public Health Nutrition, 13, 1113-1121. 
Newby, P.K. (2007). Are dietary intakes and eating behaviors related to childhood obesity? A comprehensive review of the evidence. Journal of Law Medicine \& Ethics, 35, 35-60.

Niemeier, H.M., Raynor, H.A., Lloyd-Richardson, E.E., Rogers, M.L., \& Wing, R.R. (2006). Fast food consumption and breakfast skipping: Predictors of weight gain from adolescence to adulthood in a nationally representative sample. Journal of Adolescent Health, 39, 842-849.

Nilsson, A., Andersen, L.B., Ommundsen, Y., Froberg, K., Sardinha, L.B., Piehl-Aulin, K., et al. (2009). Correlates of objectively assessed physical activity and sedentary time in children: a cross-sectional study (The European Youth Heart Study). Bmc Public Health, 9.

O'Connor, T.M., Hughes, S., Watson, K.B., Baranowski, T., Nicklas, T.A., Fisher, J.O., et al. (2010). Parenting practices are associated with fruit and vegetable consumption in pre-school children. Public Health Nutrition, 13, 91-101.

Ornelas, I.J., Perreira, K.M., \& Ayala, G.X. (2007). Parental influences on adolescent physical activity: a longitudinal study. International Journal of Behavioral Nutrition and Physical Activity, 4.

Paeratakul, S., Ferdinand, D.P., Champagne, C.M., Ryan, D.H., \& Bray, G.A. (2003). Fast-food consumption among US adults and children: Dietary and nutrient intake profile. Journal of the American Dietetic Association, 103, 1332-1338.

Patel, S.R., \& Hu, F.B. (2008). Short sleep duration and weight gain: A systematic review. Obesity, 16, 643-653.

Patro, B., \& Szajewska, H. (2010). Meal patterns and childhood obesity. Current Opinion in Clinical Nutrition and Metabolic Care, 13, 300-304.

Pearson, N., Biddle, S.J.H., \& Gorely, T. (2009). Family correlates of fruit and vegetable consumption in children and adolescents: a systematic review. Public Health Nutrition, 12, 267283.

Rampersaud, G.C., Pereira, M.A., Girard, B.L., Adams, J., \& Metzl, J.D. (2005). Review Breakfast habits, nutritional status, body weight, and academic performance in children and adolescents. Journal of the American Dietetic Association, 105, 743-760.

Rey-Lopez, J.P., Vicente-Rodriguez, G., Biosca, M., \& Moreno, L.A. (2008). Sedentary behaviour and obesity development in children and adolescents. Nutrition Metabolism and Cardiovascular Diseases, 18, 242-251.

Rhee, K. (2008). Childhood overweight and the relationship between parent behaviors, parenting style and family functioning. Annals of the American Academy of Political and Social Science, 615, 12-37.

Rhee, K.E., Coleman, S.M., Appugliese, D.P., Kaciroti, N.A., Corwyn, R.F., Davidson, N., et al., (2009). Maternal Feeding Practices Become More Controlling After and Not Before Excessive Rates of Weight Gain. Obesity, 17, 1724-1729.

Rolls, B.J., Engell, D., \& Birch, L.L. (2000). Serving portion size influences 5-year-old but not 3year-old children's food intakes. Journal of the American Dietetic Association, 100, 232-234. 
Rosenheck, R. (2008). Fast food consumption and increased caloric intake: a systematic review of a trajectory towards weight gain and obesity risk. Obesity Reviews, 9, 535-547.

Rutters, F., Gerver, W.J., Nieuwenhuizen, A.G., Verhoef, S.P.M., \& Westerterp-Plantenga, M.S. (2010). Sleep duration and body-weight development during puberty in a Dutch children cohort. International Journal of Obesity, 34, 1508-1514.

Sallis, J.F., Prochaska, J.J., \& Taylor, W.C. (2000). A review of correlates of physical activity of children and adolescents. Medicine and Science in Sports and Exercise, 32, 963-975.

Santos, J.L., Kain, J., Dominguez-Vasquez, P., Lera, L., Galvan, M., Corvalan, C., et al. (2009). Maternal anthropometry and feeding behavior toward preschool children: association with childhood body mass index in an observational study of Chilean families. International Journal of Behavioral Nutrition and Physical Activity, 6.

Shea, B.E., Harvey-Berino, J.R., \& Johnson, R.K. (2010). Watching television: how does it influence the dietary quality of children? Nutrition Bulletin, 35, 165-171.

Shi, Z.M., Taylor, A.W., Gill, T.K., Tuckerman, J., Adams, R., \& Martin, J. (2010). Short sleep duration and obesity among Australian children. Bmc Public Health, 10.

Snoek, H.M., Engels, R.C.M.E., Janssens, J.M.A.M., \& van Strien, T. (2007). Parental behaviour and adolescents' emotional eating. Appetite, 49, 223-230.

Sondergaard, H.A. \& Edelenbos, M. (2007). What parents prefer and children like Investigating choice of vegetable-based food for children. Food Quality and Preference, 18, 949-962.

Spill, M.K., Birch, L.L., Roe, L.S., \& Rolls, B.J. (2010). Eating vegetables first: the use of portion size to increase vegetable intake in preschool children. American Journal of Clinical Nutrition, 91, 1237-1243.

Storey, K.E., Hanning, R.M., Lambraki, I.A., Driezen, P., Fraser, S.N., \& McCargar, L.J. (2009). Determinants of Diet Quality Among Canadian Adolescents. Canadian Journal of Dietetic Practice and Research, 70, 58-65.

Szajewska, H., \& Ruszczynski, M. (2010). Systematic Review Demonstrating that Breakfast Consumption Influences Body Weight Outcomes in Children and Adolescents in Europe. Critical Reviews in Food Science and Nutrition, 50, 113-119.

Timlin, M.T., Pereira, M.A., Story, M., \& Neumark-Sztainer, D. (2008). Breakfast eating and weight change in a 5-year prospective analysis of adolescents: Project EAT (eating among teens). Pediatrics, 121, E638-E645.

Timperio, A., Salmon, J., Ball, K., Baur, L.A., Telford, A., Jackson, M., et al. (2008). Family physical activity and sedentary environments and weight change in children. International Journal of Pediatric Obesity, 3, 160-167.

Vagstrand, K. (2010). Sex differences among Swedish adolescents in mother-child relationships in the intake of different food groups. British Journal of Nutrition, 103, 1205-1211. 
Ventura, A.K. \& Birch, L.L. (2008). Does parenting affect children's eating and weight status? International Journal of Behavioral Nutrition and Physical Activity, 5.

Vereecken, C., Legiest, E., de Bourdeaudhuij, I., \& Maes, L. (2009). Associations Between General Parenting Styles and Specific Food-Related Parenting Practices and Children's Food Consumption. American Journal of Health Promotion, 23, 233-240.

Vereecken, C., Haerens, L., de Bourdeaudhuij, I., \& Maes, L. (2010). The relationship between children's home food environment and dietary patterns in childhood and adolescence. Public Health Nutrition, 13, 1729-1735.

Verzeletti, C., Maes, L., Santinello, M., Baldassari, D., \& Vereecken, C.A. (2010). Food-related family lifestyle associated with fruit and vegetable consumption among young adolescents in Belgium Flanders and the Veneto Region of Italy. Appetite, 54, 394-397.

Viner, R.M., \& Cole, T.J. (2006). Who changes body mass between adolescence and adulthood? Factors predicting change in BMI between 16 year and 30 years in the 1970 British Birth Cohort. International Journal of Obesity, 30, 1368-1374.

Wang, Y., Beydoun, M.A., Li, J., Liu, Y., \& Moreno, L.A. (2011). Do children and their parents eat a similar diet? Resemblance in child and parental dietary intake: systematic review and meta-analysis. Journal of Epidemiology and Community Health, 65, 177-189.

Weiss, A., Xu, F., Storfer-Isser, A., Thomas, A., Levers-Landis, C.E., \& Redline, S. (2010). The Association of Sleep Duration with Adolescents' Fat and Carbohydrate Consumption. Sleep, 33, 1201-1209.

Westerlund, L., Ray, C., \& Roos, E. (2009). Associations between sleeping habits and food consumption patterns among 10-11-year-old children in Finland. British Journal of Nutrition, $102,1531-1537$.

Wind, M., te Velde, S.J., Brug, J., Sandvik, C., \& Klepp, K.I. (2010). Direct and indirect association between environmental factors and fruit intake, mediation by psychosocial factors: the Pro Children study. Public Health Nutrition, 13, 1736-1745.

Woodruff, S.J., \& Hanning, R.M. (2008). A review of family meal influence on adolescents' dietary intake. Canadian Journal of Dietetic Practice and Research, 69, 14-22.

Woodruff, S.J., Hanning, R.M., McGoldrick, K., \& Brown, K.S. (2010). Healthy eating index-C is positively associated with family dinner frequency among students in grades 6-8 from Southern Ontario, Canada. European Journal of Clinical Nutrition, 64, 454-460.

Zeinstra, G.G., Koelen, M.A., Kok, F.J., van der Laan, N., \& de Graaf, C. (2010). Parental childfeeding strategies in relation to Dutch children's fruit and vegetable intake. Public Health Nutrition, 13, 787-796.

Zive, M.M., Frank-Spohrer, G.C., Sallis, J.F., Mckenzie, T.L., Elder, J.P., Berry, C.C., et al. (1998). Determinants of dietary intake in a sample of white and Mexican-American children. Journal of the American Dietetic Association, 98, 1282-1289. 
Zocca, J.M., Shomaker, L.B., Tanofsky-Kraff, M., Columbo, K.M., Raciti, G.R., Yanovski, S.Z., et al. (2010). Links Among Mothers' Disinhibited Eating, Children's Disinhibited Eating, and Children's Adiposity. Obesity, 18, S87.

(c) Copyright of Journal of Youth Development $\sim$ Bridging Research and Practice. Content may not be copied or emailed to multiple sites or posted to a listserv without copyright holder's express written permission. However, users may print, download or email articles for individual use. 